\title{
Smarter every day The deceleration of population ageing in terms of cognition
}

Valeria Bordone, Sergei Scherbov, Nadia Steiber

\section{Ageing}

- Increase in life expectancy

- Postponement of the onset of degenerative ageing (Vaupel 2010)

- Steadily increasing average scores on common tests of cognitive functioning,

i.e., Flynn effect

- Scant evidence on older populations (Baxendale 2010; Cristensen et al. 2013; Gerstorf et al. 2011; Rönnlund \& Nilsson 2008; Rotrou et al. 2013; Skirbekk et al. 2013)

- Little attention has been paid to subgroup differences, e.g. across education

\section{Cognitive functioning}

- Characteristic of the individual that is associated with but not determined by chronological age

- Central component of successful aging (Rowe \& Kahn 1987)

- Useful measure of differential ageing

- Some parts of the population start aging (in terms of cognition) earlier than others, education being a central factor in this regard

\section{Research questions}

\section{Do we observe a deceleration of population ageing?}
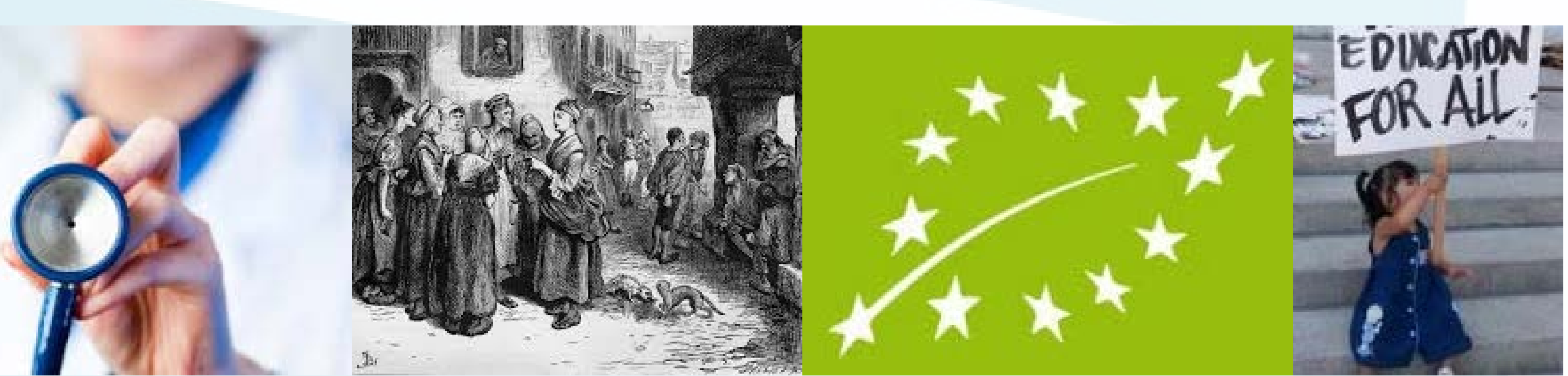

- Focus on cognitive functioning

$\rightarrow$ Do we observe a Flynn effect?

$\rightarrow$ What can explain it?
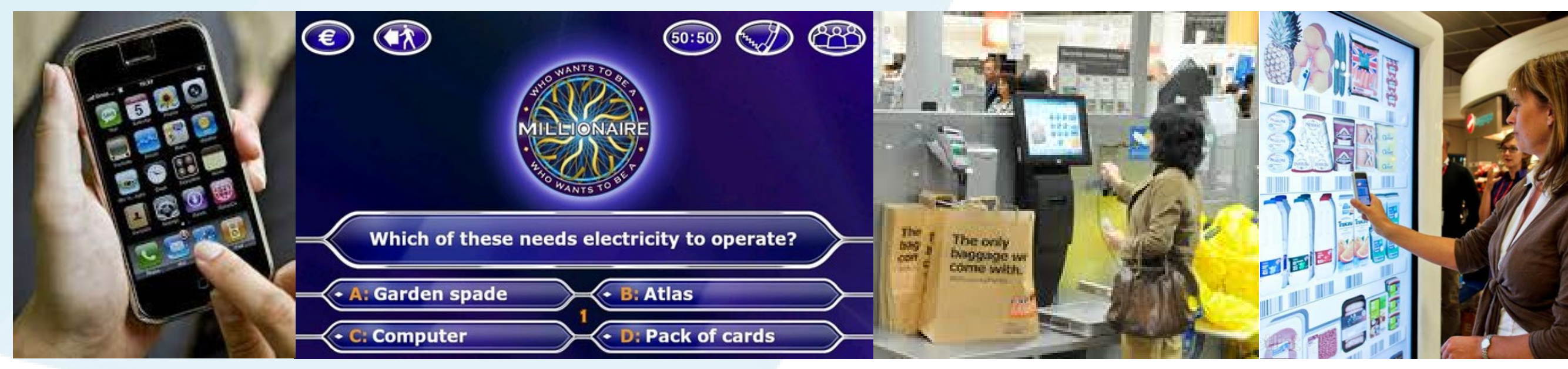

Data

- German Socio-Economic Panel 2006 \& 2012

- Age 50+

- Symbol-Digit Task (SDT 30,60, 90) taps abilities based on the mechanics of cognition

- English Longitudinal Survey of Ageing 2002 \& 2008*

( ${ }^{\star}$ refresher sample)

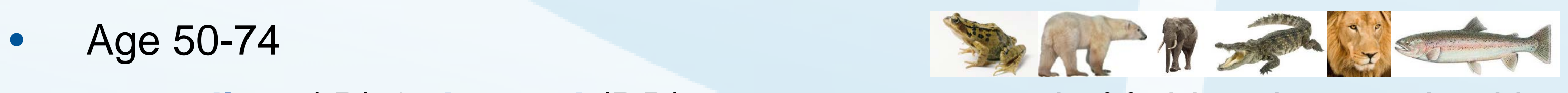

- Immediate (IR) \& delayed (DR) recall, a compound of fluid and crystallized intelligence

- Animal Naming Task (ANT) strongly based on the pragmatics of cognition

- Letter Cancellation Task (LCT), a measure of accuracy

\section{Method}

- Repeat cross-sectional approach to identify, quantify, and explain the Flynn effect

1. estimate the difference in mean cognitive test scores across 2 points in time

- explanatory variable: Flynn effect (i.e. wave dummy)

- controls: age, sex, education

2. calculate the 'constant characteristics age' (Sanderson \& Scherbov, 2013) and the 'age gain'

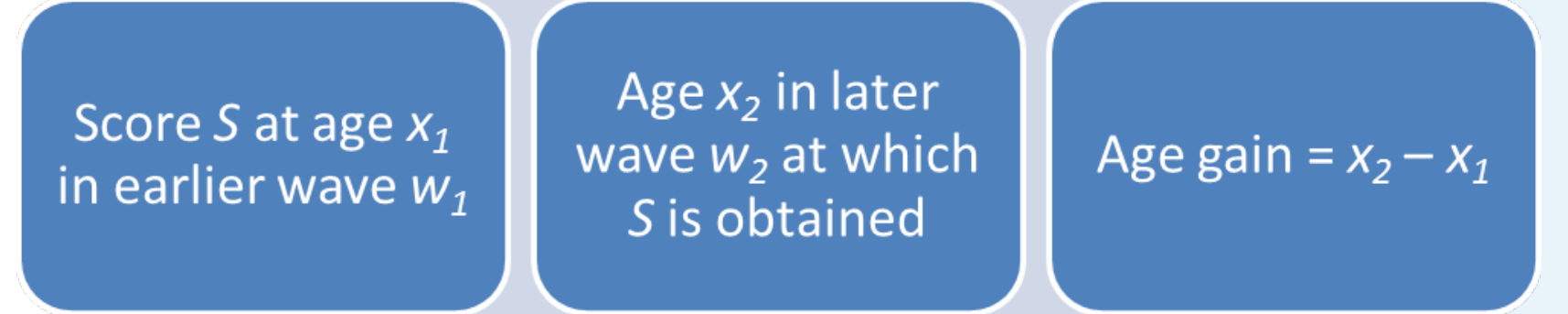

3. test if increasing technology explains the observed Flynn effect

- additional controls: use of PC and mobile

\section{The contribution of technology}

\begin{tabular}{|c|c|c|c|c|}
\hline & \multicolumn{2}{|c|}{ SOEP } & \multicolumn{2}{|c|}{ ELSA } \\
\hline & SDT90 - M1 & SDT90 - M2 & ANT - M1 & ANT - M2 \\
\hline \multirow[t]{2}{*}{ Age } & $-0.294^{\star \star \star}$ & $-0.249^{\star \star \star}$ & $-0.146^{\star \star \star}$ & $-0.120^{\star \star \star}$ \\
\hline & $(0.012)$ & $(0.013)$ & $(0.009)$ & $(0.009)$ \\
\hline \multirow[t]{2}{*}{ Flynn effect } & $2.334^{\star \star \star}$ & $1.933^{\star \star \star}$ & $0.904^{\star \star \star}$ & $0.488^{\star *}$ \\
\hline & $(0.227)$ & $(0.231)$ & $(0.169)$ & $(0.172)$ \\
\hline \multirow[t]{2}{*}{ Education ${ }^{1}$} & $0.604^{\star \star \star}$ & $0.489^{\star \star \star}$ & $4.076^{\star \star \star}$ & $3.402^{\star \star \star}$ \\
\hline & $(0.042)$ & $(0.044)$ & $(0.153)$ & $(0.164)$ \\
\hline \multirow[t]{2}{*}{ PC / internet $^{2}$} & - & $1.752^{\star \star *}$ & - & $1.314^{\star \star *}$ \\
\hline & & $(0.281)$ & & $(0.142)$ \\
\hline \multirow[t]{2}{*}{ Mobile $^{3}$} & - & $1.248^{\star \star *}$ & - & $0.540^{* \star *}$ \\
\hline & & $(0.336)$ & & $(0.135)$ \\
\hline $\mathrm{N}$ & 4,891 & 4,891 & 9,572 & 9,572 \\
\hline $\mathrm{R} 2$ & 0.166 & 0.179 & 0.125 & 0.147 \\
\hline
\end{tabular}

Table 3. Coefficients and se from linear regressions. Notes: 1 . Years of education in SOEP, High vs. low in ELSA: 2 household in SOEP, use in ELSA; 2. in household in SOEP, owner in ELSA. All models control also for sex.

\section{Descriptives}

\begin{tabular}{|l|c|c|c|c|}
\hline & Mean $(\mathbf{s . d .})$ & Mean $(\mathbf{s . d})$. & $\min$ & $\max$ \\
\hline SOEP & $2006(\mathrm{~N}=\mathbf{2 , 0 1 3})$ & $2012(\mathrm{~N}=2,878)$ & & \\
\hline SDT30 & $7.1(3.4)$ & $7.4(3.3)$ & 0 & 24 \\
\hline SDT60 & $15.2(6.5)$ & $16.2(6.0)$ & 0 & 38 \\
\hline SDT90 & $23.2(9.0)$ & $24.9(8.1)$ & 0 & 54 \\
\hline ELSA & $2002(\mathrm{~N}=8,170)$ & $2008(\mathrm{~N}=1,402)$ & & \\
\hline ANT & $20.4(6.1)$ & $21.6(6.3)$ & 0 & 55 \\
\hline IR & $5.8(5.8)$ & $6.1(1.6)$ & 0 & 10 \\
\hline DR & $4.4(2.0)$ & $4.8(1.9)$ & 0 & 10 \\
\hline LCT & $79.8(13.8)$ & $82.0(12.0)$ & 0 & 100 \\
\hline
\end{tabular}

Table 1. Mean and s.d. of the cognitive test scores.

\section{Results}

- People interviewed 6 years later match 2 symbols more and name 1 animal more
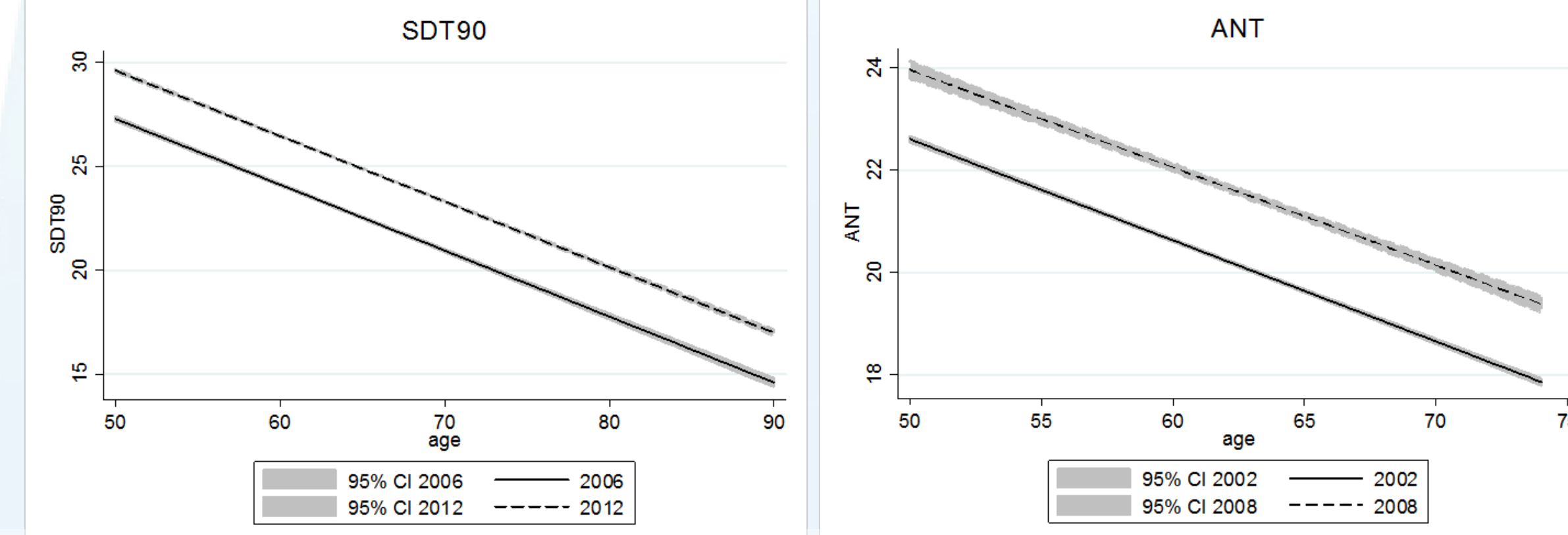

Figure 1. Predicted age-cognition profiles by survey wave. Linear fit over age, by survey year; controls: education, sex.

\begin{tabular}{|c|c|c|c|c|c|c|c|}
\hline & \multicolumn{3}{|c|}{ SOEP } & \multicolumn{4}{|c|}{ ELSA } \\
\hline & SDT30 & SDT60 & SDT90 & ANT & IR & DR & LCT \\
\hline Age gain & 4.9 & 6.4 & 7.9 & 6.2 & 4.8 & 5.7 & 7.5 \\
\hline
\end{tabular}

Table 2. Age-gains for the different cognitive tests.

\section{Conclusion}

- The results of this study show the existence of a Flynn effect on 50+ year olds

- The Flynn effect remains constant over age and education

- The age-cognition profile does not vary with the educational attainment of test participants

- Increasing levels of education over cohorts may have driven a good part of the Flynn effect in earlier decades

- Technology in terms of PC and mobile phone use contributes, to a certain extent, to the explanation of the Flynn effect

- Other possible explanations that require further research:

- "Social multiplier" effect

- Modern technology use in everyday life, other than use of PC and mobile phone 